\title{
Electrodeposition of Silver and Copper/Silver Multilayer on Ruthenium Substrate as a Potential New Metal Interconnect for Integrated Circuits
}

\author{
Chris Cheng, Tiruchirapalli Arunagiri, and Oliver Chyan ${ }^{\dagger}$ \\ Department of Chemistry \\ University of North Texas \\ Denton, Texas 76203 USA
}

Received:March 11, 2003 Accepted: May 15, 2003

\begin{abstract}
As the demand for faster and cheaper integrated circuits prevalent in today's technology continues to rise, there is a challenge to produce even smaller and faster circuits in less time and for less cost. Our work explores the superior conductivity of silver metal for the application as a more conductive metal interconnects in next generation integrated circuits. In this work, ruthenium was chosen as the diffusion barrier platform on which a precise and uniform coating of silver would be deposited electrochemically. However, the adhesion testing revealed poor adhesion between deposited $\mathrm{Ag}$ thin film and its $\mathrm{Ru}$ substrate. The adhesion problem was corrected by installing a thin $\mathrm{Cu}$ priming layer on $\mathrm{Ru}$ prior to $\mathrm{Ag}$ deposition. A two-steps $\mathrm{Ag}$ plating protocol was developed to overcome the unwanted $\mathrm{Ag}$ displacement reaction with $\mathrm{Cu}$ and achieved the preparation of $\mathrm{Ag} / \mathrm{Cu} / \mathrm{Ru}$ multiplayer, which showed good adhesion after peel test.
\end{abstract}

\section{INTRODUCTION}

Creating smaller and faster integrated circuits (IC) (Figure 1), while maintaining high efficiency, is a continuous goal of the one hundred and fifty billion dollar semiconductor industry. Creating smaller and faster IC will impact everyday life by shrinking the size of electrical appliances while making these appliances faster and better than ever before. Also creating smaller and faster IC will allow the construction of more powerful computer, which will allow scientists and mathematicians of the future to calculate problems faster and obtain results with more accuracy.

Currently, the integrated circuits can be made smaller than $0.13 \mu \mathrm{m}$ when using copper $(\mathrm{Cu})$ as the interconnect material. Before, interconnects were made with other materials such as aluminum [1-5]. In the sub $0.13 \mu \mathrm{m}$ generation integrated circuits, copper will completely replace aluminum as

$\mp$ Author for correspondence

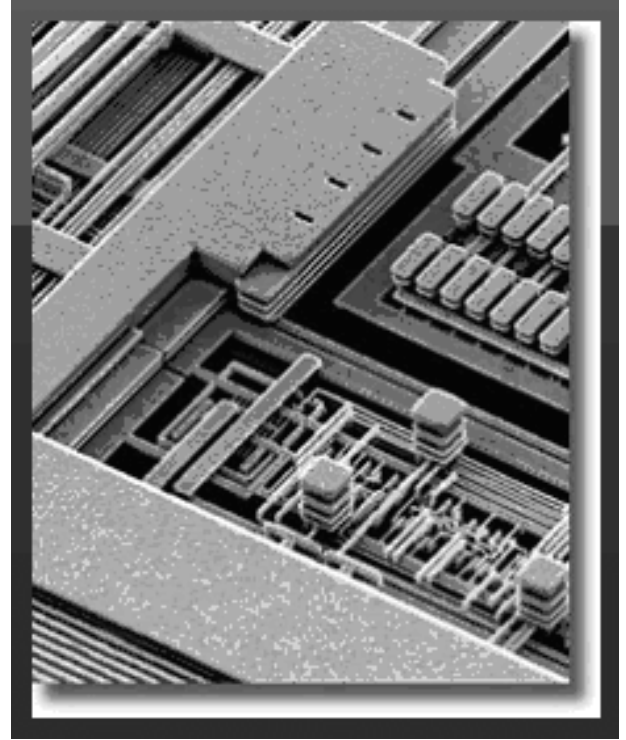

Figure 1. Cu interconnections for a modern microprocessor. Insulating interlayer dielectrics have been removed by dry etching. Source: http://www.research.IBM.com 

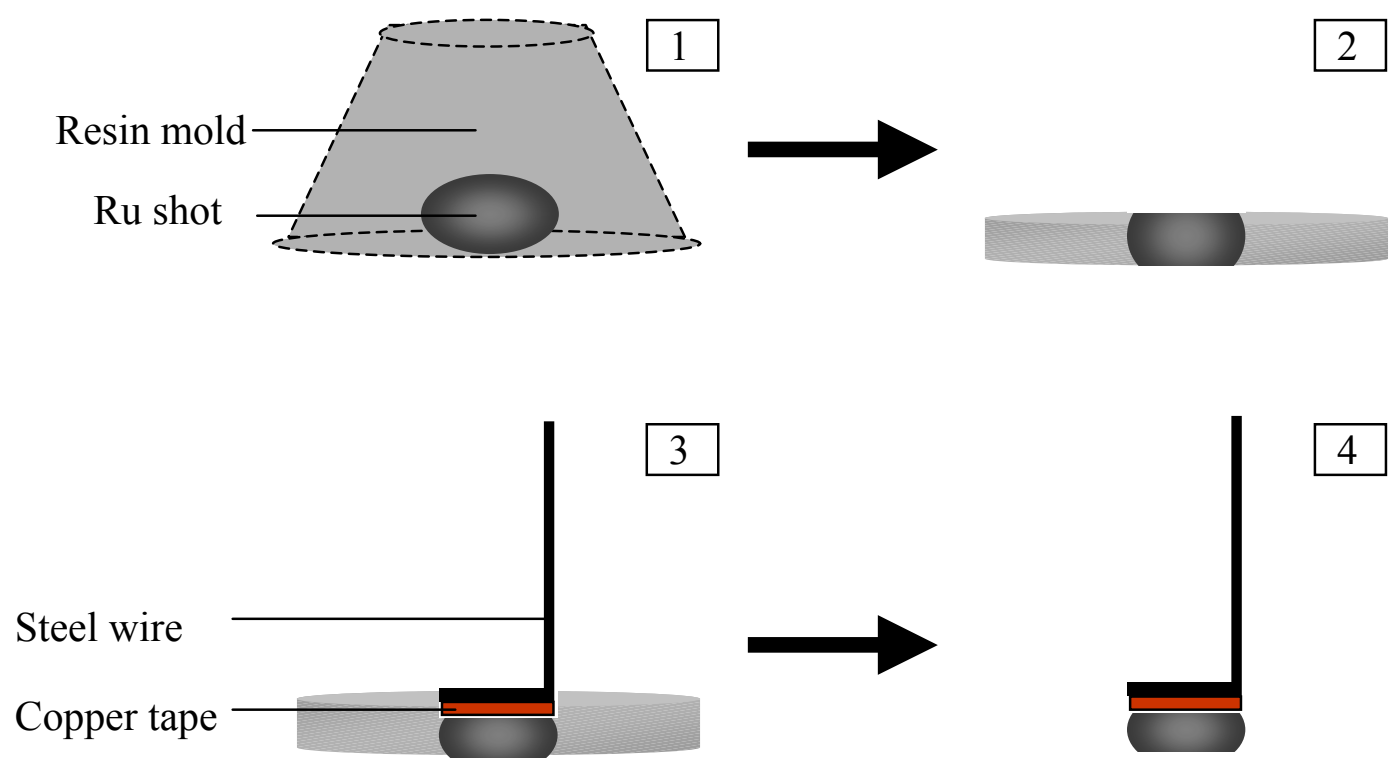

Figure 2. Procedures for Preparing Ru electrode: 1) An Ru shot is encased in a resin mold; 2) Both sides of the shot are exposed; one side is polished to a mirror finish; 3 ) The unpolished side is connected to a steel wire with conductive copper tape; and 4) The shot is removed from the mold and is ready to be used for electrochemical experiments

the new interconnect material due to its favorable electrical conductivity $(1.7 \mu \Omega . \mathrm{cm})$ and superior resistance to electromigration [1]. Chips with more conductive $\mathrm{Cu}$ interconnects and low-k interlayer dielectrics will operate consuming less power and at significantly higher speeds due to decreased resistance-capacitance coupling delay. To prevent contamination caused by the interconnect material diffusing through interlayer dielectrics into the silicon substrate, diffusion barriers are needed to contain and protect the interconnect material. Functional interconnect barriers must have a good adhesion to both the interconnect metal material and the interlayer insulating dielectrics. It must also provide a conductive plating platform for the $\mathrm{Cu}$ interconnect metal to plate on. Our prior group finding demonstrated that Ruthenium $(\mathrm{Ru})$ is a good candidate as a new diffusion barrier because $\mathrm{Ru}$ is an air stable transition metal with high melting point $\left(2310^{\circ} \mathrm{C}\right)$ and is highly thermally and electrically conductive [6]. In addition, our experimental result indicated through X-Ray Diffraction that there is a lack of metallurgical interaction between copper and ruthenium even when the sample has been annealed to elevated temperatures. This shows that copper and ruthenium is unlikely to be involved in any interaction, thus Ru can be used as a stable diffusion barrier.

Silver $(\mathrm{Ag})$ is a very promising candidate for a new interconnect material because of its innate characteristics of having the lowest resistivity $(1.6 \mu \Omega . \mathrm{cm})$ of all known common materials except superconductors [7]. In this paper, we explore the electrodeposition of $\mathrm{Ag}$ and $\mathrm{Ag} / \mathrm{Cu}$ thin-film multiplayer on $\mathrm{Ru}$ as a future candidate for metal interconnect/barrier structure by electrochemistry methods and optical microscopy. Cyclic voltammetry was used to determine the exact deposition and stripping potential of $\mathrm{Ag}$ and $\mathrm{Cu}$ on $\mathrm{Ru}$ electrode surface. We also achieved fine control of the thickness of our electrodeposited $\mathrm{Cu}$ and $\mathrm{Ag} / \mathrm{Cu}$ thin layers and evaluated the adhesion of deposited metal thin layers to its $\mathrm{Ru}$ substrate. Our result suggest that a thin $\mathrm{Cu}$ priming layer promotes the overall mechanical integrity of $\mathrm{Ag} / \mathrm{Cu} / \mathrm{Ru}$ multiplayer stack structure as demonstrated by the Scotch tape peel test. 


\section{EXPERIMENTAL}

\section{a. Ruthenium Electrode Preparation}

Ruthenium shots (ESPI Inc.) were meticulously polished (Figure 2) using the following procedure. First the shot was encased in a mixture of metallographic resin and hardener epoxy (Leco Corp.) contained in a plastic mold. Our mold was the cut off end of a big pipette tip. After letting the epoxy set, the mold cut away, and using the standard polishing procedure as described below, the surface of the ruthenium shot was polished to a mirror finish. Coarse and fine grinding was done using silicon carbide (SiC) polishing pads (Allied Products Inc.) with gradually decreasing grit sizes. Starting with the 60 grit size pad, then 180 grit and 320 grit size pad, and finally finishing grinding at 600 grit size pad. Fine polishing was accomplished with polycrystalline diamond suspensions (Allied Products Inc.) of decreasing grain sizes (6 $\mu \mathrm{m}$ to $0.05 \mu \mathrm{m})$. After each polish, the ruthenium shot would be sonicated for five minutes to remove in any particles that may cause cross contamination. After achieve a mirror surface, the ruthenium shot is carefully attached to a steel wire using conductive copper tape as the adhesive agent and separated from the mold. The ruthenium electrode is then submerged very carefully in Aqua Regia made from $8.2 \mathrm{~mL}$ of $\mathrm{H}_{2} \mathrm{SO}_{4}$ and $1.8 \mathrm{~mL} \mathrm{HNO}_{3}$ for 2 minutes in order to chemically clean the electrode. Then the ruthenium shot with the steel wire attached is electrochemically cleaned.

\section{b. Electrochemical Investigation}

The electrochemical experiments, cyclic voltammetry (CV) and chronoamperometry (CA), were done using an EG\&G Model M273 Potentiostat/Galvanostat in a $0.5 \mathrm{M}$ sulfuric acid $\left(\mathrm{H}_{2} \mathrm{SO}_{4}\right)$ system with an ruthenium working electrode, a silver/silver chloride reference electrode $(+0.197$ vs. $\mathrm{SHE}$ ), and a platinum counter electrode (Figure 3 ). All solutions were made using high purity copper sulfate $\left(\mathrm{CuSO}_{4} \cdot 5 \mathrm{H}_{2} \mathrm{O}\right)$ (Aldrich), silver sulfate $\left(\mathrm{Ag}_{2} \mathrm{SO}_{4}\right)$ (Aldrich), and sulfuric acid $\left(\mathrm{H}_{2} \mathrm{SO}_{4}\right)$ (Mallinckrodt) in ultra-pure water (Millipore).

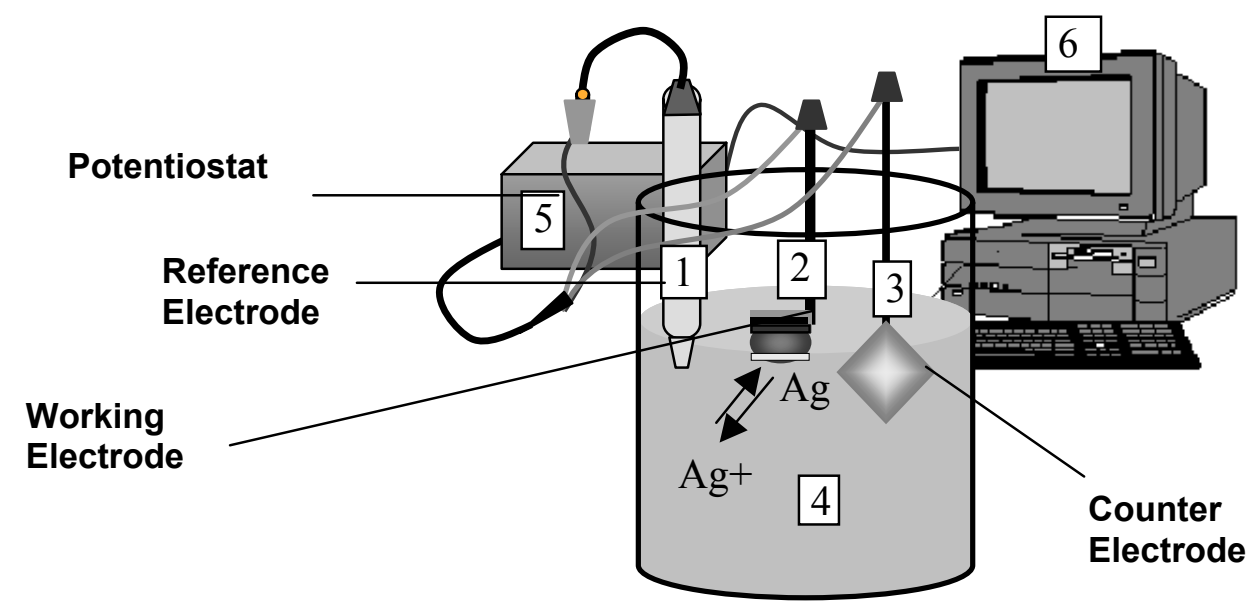

Figure 3. Electrochemistry Setup. The Electrochemical cell contained the following: 1) a $\mathrm{Ag} / \mathrm{AgCl}$ reference electrode; 2) a working $\mathrm{Ru}$ electrode; 3) A platinum counter electrode; 4) a electrolyte based in 0.5M sulfuric acid; 5) a EG\&G Model M273 Potentiostat/Galvanostat; and 6) a computer to record the data. 
C. Microscopy Investigation
Characterization

All photos were taken using a Nikon Digital Network Camera DN100 attached to a Nikon Microscope ME600L using dark and bright field microscopy. Dark field microscopy is a technique in which light is channeled through the objective lens and is shone at the surface of the sample at an angle, thus allowing only some light to reflect off the sample and back through the objective lens. Therefore, with dark field microscopy, one can exam the sample with better lateral contrast. Bright field microscopy is a technique in which light is channeled through the objective lens and is shone directly onto the surface of the object, thus allowing almost all of the light to reflect off the sample and back through the objective lens. An advantage of bright field microscopy is that I can see the object in its actual colors. Adhesion of a metal to an electrode substrate is performed by a peel test. A piece of Scotch ${ }^{\mathrm{TM}}$ brand tape was pressed onto the electrode and then quickly removed. If little or none of the metal was peeled off from the electrode surface, then the adhesion of the metal to the electrode is considered good. The Scotch tape peel test is commonly used in IC industry to evaluate the adhesion property of thin film.

\section{RESULTS AND DISCUSSION}

\section{a. Electrodeposition of Silver on Ruthenium}

To find out how silver deposits on ruthenium, $\mathrm{Ag}$ was electrodeposited on a freshly polished and cleaned Ru electrode in a $0.5 \mathrm{M} \mathrm{H}_{2} \mathrm{SO}_{4}$ solution contained $0.01 \mathrm{M}$ $\mathrm{Ag}_{2} \mathrm{SO}_{4}$. By checking the background cyclic voltammetry in $\mathrm{H}_{2} \mathrm{SO}_{4}$ alone and measuring the open circuit potential (OCP) value of the as prepared electrode, we were able to determine that the $\mathrm{Ru}$ electrode was clean and had a good electrical contact. This ruthenium electrode was then scanned in the $\mathrm{Ag}_{2} \mathrm{SO}_{4} / \mathrm{H}_{2} \mathrm{SO}_{4}$ solution, starting from the OCP value $(+0.408 \mathrm{~V})$ down to a negative maximum of $-0.2 \mathrm{~V}$. It was then scanned to the positive maximum of $+1.0 \mathrm{~V}$, and finally back to the original OCP value $(+.408 \mathrm{~V})$. According to the resulting cyclic voltamogram (Figure 4), silver cathodic deposition begins at around $+0.4 \mathrm{~V}$ at negative potential scan and shows a peak at $+0.35 \mathrm{~V}$ while silver anodic stripping begins at around $+0.4 \mathrm{~V}$ at reverse scan and peaks at $+0.5 \mathrm{~V}$.

After silver was deposited on the ruthenium electrode surface, the result was viewed under the optical microscope to examine the morphological quality of the deposited $\mathrm{Ag}$ Film on $\mathrm{Ru}$. As shown in Figure 5, deposited silver film show submicron scale roughness under 200X magnification. Subsequently, a peel test was conducted to test the quality of the adhesion of silver to the ruthenium surface. After conducting a peel test, almost all the deposited silver layer on the ruthenium substrate was removed by the peel test, hence, silver does not adhere well to a ruthenium surface.

A strong adhesion between metal interconnect $(\mathrm{Ag})$ and its barrier substrate $(\mathrm{Ru})$ is critical since the advanced fabrication of metal interconnect microstructures required strong mechanical strength to withstand the demanding chemical-mechanical planarization process, currently used in IC fabrication. To effectively electroplate silver on ruthenium with good adhesion, we explore the approach to install an intermediate metal priming layer on ruthenium before silver deposition. This layer must have good adhesion to ruthenium electrode surface and silver must have a good adhesion to his layer. Also, the material used for this layer must also be a good conductor of electricity. The material we chose to use as the intermediate layer is copper.

\section{a. Electrodepositon of Copper on Ruthenium}

A system almost identical to the one used for silver electroplating was used for copper electroplating. Copper was electroplated in a $0.5 \mathrm{M} \mathrm{H}_{2} \mathrm{SO}_{4}$ system with $0.05 \mathrm{M} \mathrm{CuSO} \mathrm{C}_{4} \cdot 5 \mathrm{H}_{2} \mathrm{O}$. A freshly cleaned ruthenium electrode was scanned (Figure 6 ) starting from the OCP value $(+0.408 \mathrm{~V})$ down to a negative maximum of $-0.2 \mathrm{~V}$. The ruthenium was then to scanned to the positive maximum of $+1.0 \mathrm{~V}$, and finally back to the original open circuit potential value $(+.408 \mathrm{~V})$. Copper deposition begins at $0.05 \mathrm{~V}$ at the negative potential scan and peaks at $-0.15 \mathrm{~V}$ while copper stripping 


\section{Ag deposition on Ru electrode}

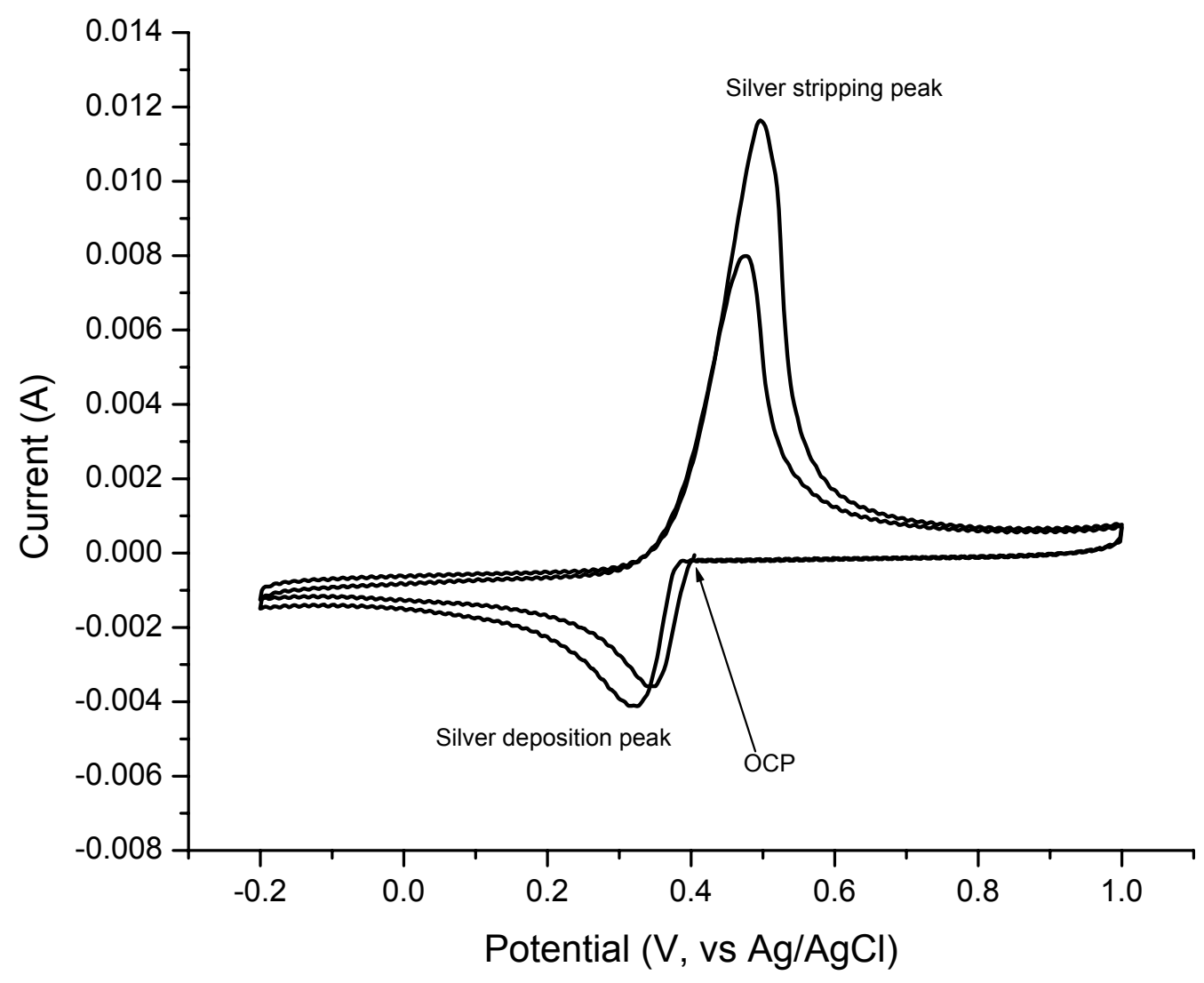

Figure 4. Cyclic voltamogram showing the deposition $(+0.35 \mathrm{~V})$ and stripping $(+0.5 \mathrm{~V})$ peaks of the silver on ruthenium electrode in $0.01 \mathrm{M} \mathrm{Ag}_{2} \mathrm{SO}_{4} / 0.5 \mathrm{M} \mathrm{H} \mathrm{H}_{2}$ solution.

onsets at $0.0 \mathrm{~V}$ at the reverse scan and peaks at $+0.15 \mathrm{~V}$. It is interesting to note that $\mathrm{Cu}$ deposition took place at the more negative potential as compared to the $\mathrm{Ag}$ deposition (+0.4 V, Figure 5) on Ru electrode. The observation is consistent with the more positive standard reduction potential of $\mathrm{Ag}^{+} / \mathrm{Ag}$ half-cell reaction than $\mathrm{Cu}^{2+} / \mathrm{Cu}$ half-cell reaction. ${ }^{7}$

After the $\mathrm{Cu}$ deposition potential was determined by $\mathrm{CV}$, we proceeded to prepare a well-controlled copper priming layer on ruthenium by chronoamperometry (CA). The ruthenium electrode was held at a constant potential of $-0.4 \mathrm{~V}$ for 5 seconds, the thickness of deposited copper layer on top of the ruthenium was calculated based on the Faradaic law taking into account for the two electron transfer per $\mathrm{Cu}$ reduction and assuming $100 \%$ plating efficiency. With a known Ru electrode area, the thickness of our copper deposition was determined to be about 575 monolayers (ML) thick. After deposition, the $\mathrm{Cu}$ deposited $\mathrm{Ru}$ electrode was examined under the optical microscope and found to be much more even and smooth compared to the $\mathrm{Ag} / \mathrm{Ru}$ surface. Furthermore the subsequent peel test showed as deposited $\mathrm{Cu}$ film adhered strongly on the Ru substrate.

b. Electrodeposition of Silver on a
Copper/Ruthenium Substrate

After depositing a layer of copper on a ruthenium electrode, the electrode was 


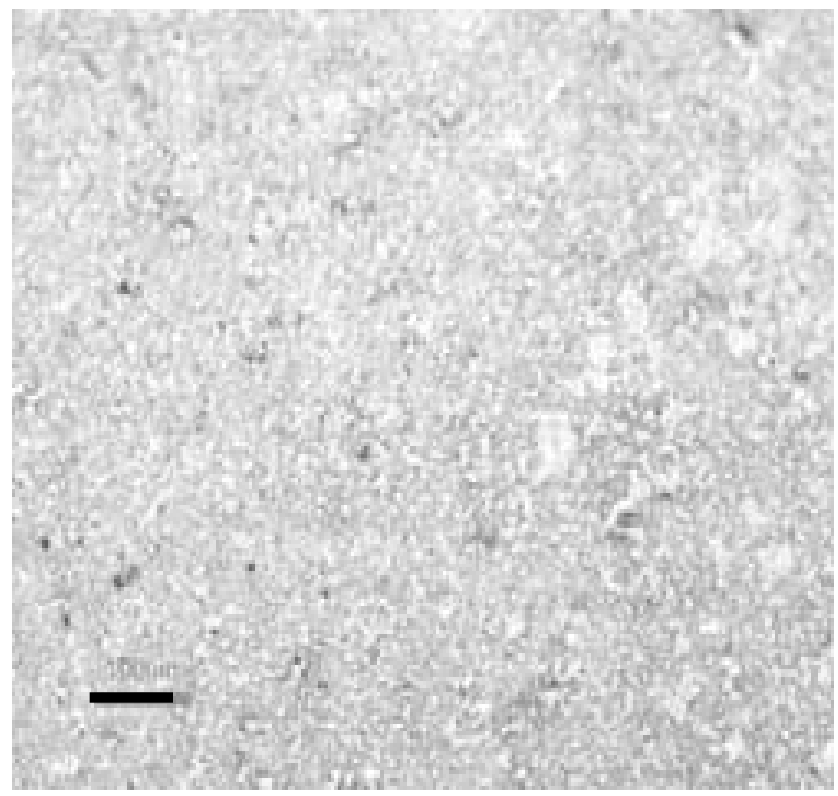

Figure 5. Electrodeposited Silver layer on ruthenium electrode (the black line at lower left is 100 $\mu \mathrm{m}$ in length).

transferred to an electrochemical system with a silver solution for electroplating. However, the copper on Ru electrode gets displaced by silver quickly when left in a silver solution with no potential being applied. The spontaneous displacement reaction is driven by the difference of standard reduction potentials between silver $(+0.799 \mathrm{~V})$ and copper $(+0.342 \mathrm{~V})$ half-cell reactions. The standard reduction potentials tell us which reduction reaction will be more favorable. A reduction reaction with a higher positive potential is more thermodynamically favorable than a reduction reaction with a low reduction potential.

To overcome this problem, we designed an Ag plating protocol to allow the $\mathrm{Cu} / \mathrm{Ru}$ electrode to be held at a negative potential in $0.5 \mathrm{M} \mathrm{H}_{2} \mathrm{SO}_{4}$ bath, and then spiked with a concentrated $\mathrm{Ag}_{2} \mathrm{SO}_{4}$ solution so that the deposition of silver to copper occurs before the displacement of copper by silver ion reduction. Using a ruthenium electrode that was electroplated with copper 575 monolayers thick, a chronoamperometry was conducted in a $6.7 \mathrm{~mL}$ of $0.5 \mathrm{M} \mathrm{H}_{2} \mathrm{SO}_{4}$ solution while holding $\mathrm{Cu} / \mathrm{Ru}$ electrode at $0.2 \mathrm{~V}$. After 15 seconds, $3.3 \mathrm{~mL}$ of concentrated $(0.1 \mathrm{M}) \mathrm{Ag}_{2} \mathrm{SO}_{4}$ solution was added to create a plating bath of $0.003 \mathrm{M}$
$\mathrm{Ag}_{2} \mathrm{SO}_{4}$ in $0.5 \mathrm{M} \quad \mathrm{H}_{2} \mathrm{SO}_{4}$. The $\mathrm{Cu} / \mathrm{Ru}$ electrode remained under potential control in the bath to receive $\mathrm{Ag}$ deposition for an additional 45 seconds. Immediately after the potential holding, the electrode was removed to avoid any further displacement. After the deposition, the result was examined under the microscope to examine the quality of the smoothness and evenness of the surface coverage. After observation, a peel test was conducted to test the quality of the adhesion of silver to the copper/ruthenium substrate. As shown in Figure 7, almost all of the silver remained on the copper/ruthenium substrate after peel test. The new Ag plating approach proves that copper works as an effective priming layer between ruthenium substrate and silver layer, thus allowing formation of a stable silver/copper/ruthenium multiplayer.

\section{SUMMARY AND FUTURE WORK}

This work concludes that silver and silver/copper/ruthenium multilayer structures can be prepared by electrodeposition technique. To circumvent the poor adhesion problem, silver can be electrodeposited on ruthenium by first electrodepositing a thin layer of copper on to ruthenium. Another 


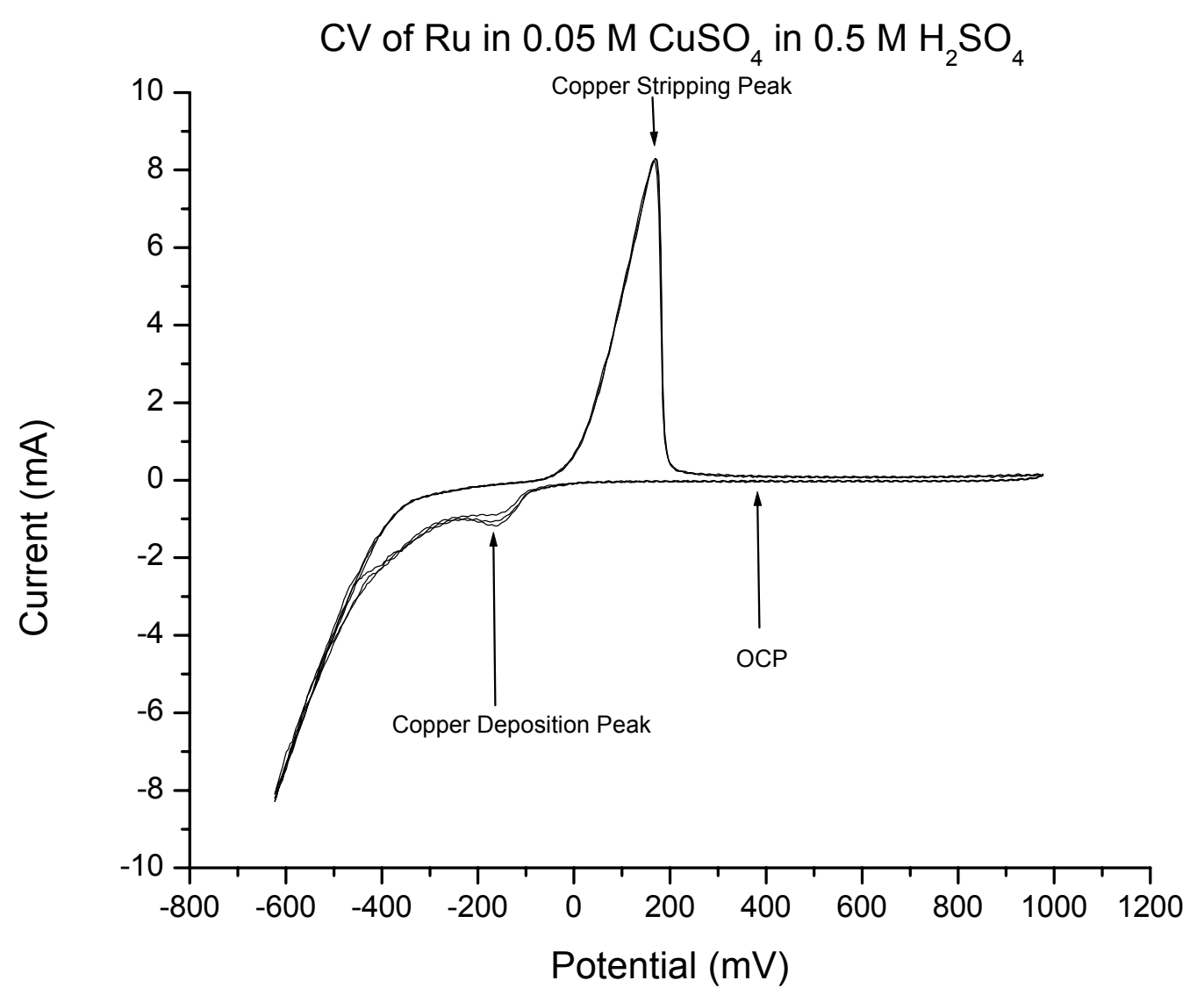

Figure 6. Cyclic voltamogram showing the deposition $(-0.15 \mathrm{~V})$ and stripping $(+0.15 \mathrm{~V})$ peaks of $\mathrm{Cu}$ on ruthenium electrode in acidic copper sulfate solution.

problem is that silver tends to displace copper priming layer before silver can be plated on to copper. One way that we solved this problem was through holding the potential at a constant negative voltage to protect $\mathrm{Cu}$ and then spiking the sulfuric acid solution with silver solution to initiate the $\mathrm{Ag}$ plating. Our research laid preliminary groundwork for further investigation of the silver/copper/ruthenium multiplayer to be used as a potential interconnect and diffusion barrier system in the next generation integrated circuits. Future work include optimizing the multilayer deposition method to improve thickness control and characterizing the $\mathrm{Ag} / \mathrm{Cu} / \mathrm{Ru}$ multiplayer under high temperature annealing condition to study its interdiffusion behavior.

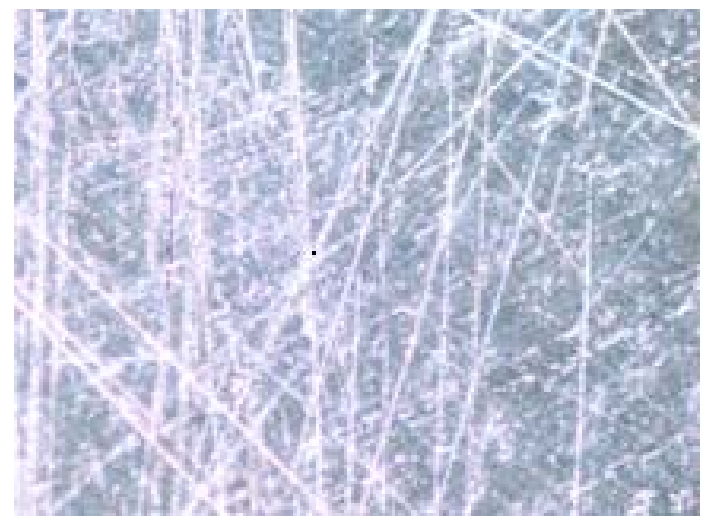

Figure 7: The optical image of an $\mathrm{Ag} / \mathrm{Cu} / \mathrm{Ru}$ multiplayer electrode after a peel test. Notice the silver remain adheres on the $\mathrm{Cu} / \mathrm{Ru}$ surface, the sub-micron scratch marks are resulting from polishing. 


\section{ACKNOWLEDGEMENTS}

The authors gratefully acknowledge the Robert A. Welch Foundation and Texas Advanced Technology Program for financial support of this work. We also thank Texas Instruments for a generous gift of silicon wafers. Chris Cheng gratefully acknowledges a summer research scholarship from the Texas Academy of Mathematics and Science (TAMS) at UNT and John Sarik for assistance in preparation of this manuscript.

\section{REFERENCES}

1. S. P. Murarka, I. V. Verner, and R. J. Gutmann, Copper-Fundamental Mechanisms for Microelectronic Applications (Wiley Interscience, New York, 2000).
2. J. N. Steigerwald, S. P. Murarka, and R. J. Gutmann, Chemical-Mechanical Planarization of Microelectronic Materials. (Wiley Interscience, New York, 1997).

3. Zhao, B; "Method of making a damascene metallization," United States Patent \#5,736,457, SEMATECH, Austin, Texas, April 1998.

4. J. Pallean, J. C. Oberline, F. Braud, J. Torres, J. L. Mermet, M. Mouche and A. Ermolieff, J. Mat. Res. Soc. Proc., 337, 225 (1994).

5. P. K. Wu, G. R. Yang and T. M. Lu, Appl. Phys. Lett., 65, 508 (1994).

6. O. Chyan, T. Arunagiri and T. Ponnuswamy, J. Electrochem. Soc., 2003 (in press).

7. Handbook of Chemistry and Physics, D. R. Lide (editor), CRC Press, 1997.

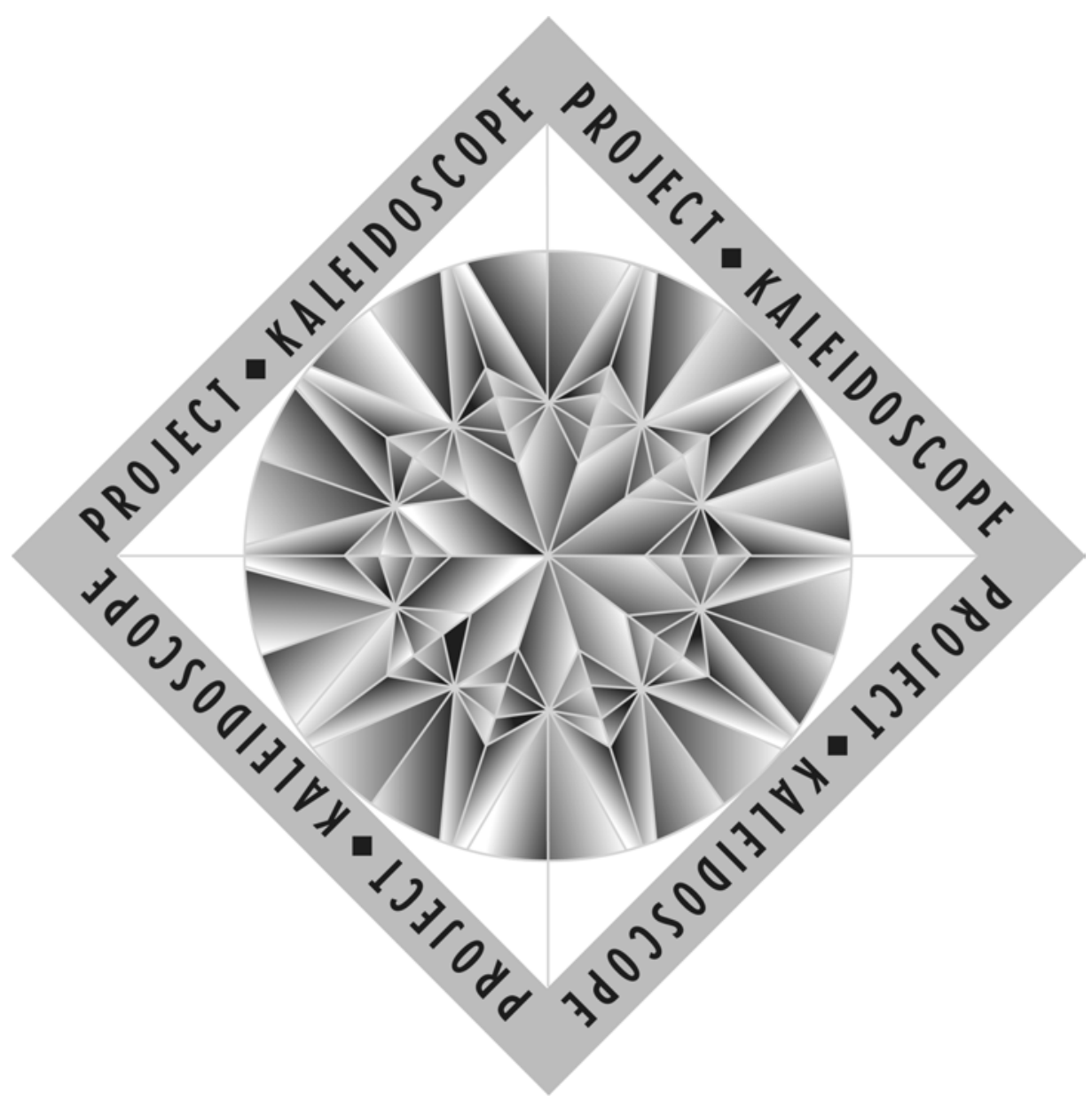

http://www.pkal.org 